\title{
Performance Improvement of Aperture Coupled MSA through Si Micromachining
}

\author{
Brijesh Kumar Soni ${ }^{1,2}$, Kamaljeet Singh ${ }^{1}$, Amit Rathi ${ }^{2, *}$, Sandeep Sancheti ${ }^{3}$ \\ ${ }^{1}$ U R Rao Satellite Centre, Bengaluru, India \\ ${ }^{2}$ Manipal University Jaipur, Jaipur, India \\ ${ }^{3}$ Marwadi University, Rajkot, India \\ Corresponding Author*-amitrathi1978@gmail.com
}

Received: June 14, 2021. Revised: December 12, 2021. Accepted: January 9, 2022. Published: January 10, 2022.

\begin{abstract}
In recent times rectangular patch antenna design has become the most innovative and popular subject due to its advantages, such as being lightweight, conformal, ease to fabricate, low cost and small size. In this paper design of aperture coupled microstrip patch antenna (MSA) on high index semiconductor material coupled with micromachining technique for performance enhancement is discussed. The performance in terms of return loss bandwidth, gain, cross-polarization and antenna efficiency is compared with standard aperture coupled antenna. Micromachining underneath of the patch helps in to reduce the effective dielectric constant, which is desirable for the radiation characteristics of the patch antenna. Improvement 36 percent and 18 percent in return loss bandwidth and gain respectively achieved using micromachined aperture coupled feed patch, which is due to the reduction in losses, suppression of surface waves and substrate modes. In this article along with design, fabrication aspects on $\mathrm{Si}$ substrate using MEMS process also discussed. Presented antenna design is proposed antenna can be useful in smart antenna arrays suitable in satellite, radar communication applications. Two topologies at $\mathrm{X}$-band are fabricated and comparison between aperture coupled and micromachined aperture coupled are presented.

Index Terms-Microstrip Patch Antenna, Aperture Coupled, Micromachining, High Resistivity Silicon
\end{abstract}

\section{INTRODUCTION}

With the advancement of the Radio Frequency Integrated Circuits (RFIC) technology, the realization of a highfrequency integrated system on a monolithic substrate is possible. The main building block of RFIC is silicon semiconductor material, which can be used for both MEMS as well as RFIC technology. The main advantages with systems fabricated using RFIC technology are improved systems performance and cost advantage. Successful heritage has been established for high frequency and speed analog and digital circuits for example Low Noise Amplifier (LNA), Power Amplifiers (PA), Synthesizers and Oscillators, etc fabricated using RFIC technology, which revolutionized the total communication system. These circuits such as are the main building block of the communication system.

Microstrip antenna technology has enormous attractive features [1-4] such as lightweight, conformal design, easy to fabricate lower cost and compact size. The main design requirement of the microstrip antenna is to maximize radiation efficiency and bandwidth, requiring patch and feed network be printing on low and high dielectric constant material respectively.

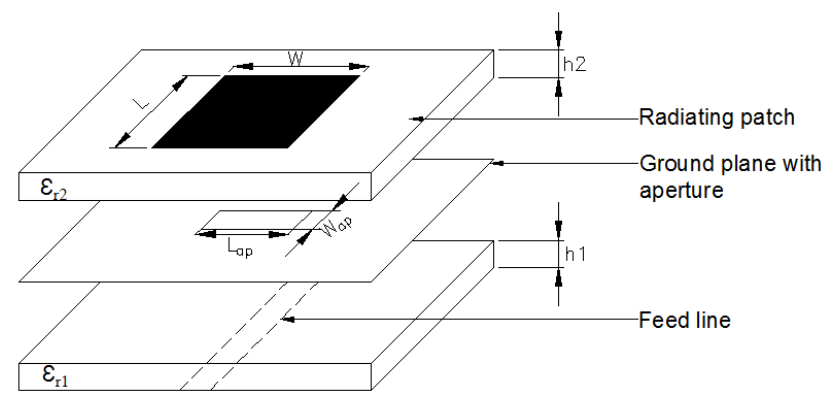

Fig. 1 Aperture coupled Microstrip patch antenna

Microstrip feed is the simplest one but due to spurious radiation, it limits bandwidth and leads to poor crosspolarization. Spurious radiation can be minimized by the selection of aperture coupled feed [5]. With aperture 
coupled feed, field is coupled through a slot in the ground plane and the feed is separated with a patch through the ground plane. The geometry of the aperture coupled patch antenna is illustrated in figure 1. This type of feed has the advantage of, no physical contact between the feed and radiating patch and independent optimization of antennas and feed network. Aperture coupled patch has wider bandwidth and improved isolation between antennas and the feed network. the of

Microstrip antenna fabricated using RFIC technology [6] can easily be integrated with front-end circuitry. However integrated system performance is limited due to the fabrication of patch on $\mathrm{Si}$ material which is having low resistivity and high dielectric constant. Crosstalk and Poor electric insulation between active and passive circuits are caused by low resistivity. Another limiting parameter is surface wave loss. These surface wave losses result in a narrow bandwidth, degraded radiation pattern and poor radiation efficiency. Surface wave losses can be minimized by selectively etching out material underneath of the patch, which in turn synthesizes the patch as low dielectric constant material. The process of selectively removal of the silicon substrate material underneath the patch antenna is known as micromachining [7]. Normally Bulk micromachining is being used to remove the material. High Resistivity Silicon with deposition of oxide, polyimide layer [8-10] can result in suppression of cross talk and parasitics. Semiconductor with bulk resistivity of more than $1 \mathrm{~K} \Omega-\mathrm{cm}$ classified as high resistivity substrate. The equivalent transmission model of the Microstrip line is shown in figure 2. Here the shunt conductance $G$ represents the current induced in the dielectric representing dielectric losses. With a high resistivity substrate, the contribution of conductance is minimal compared with capacitance for dielectric losses. As a result, choosing $\mathrm{Si}$ with a high resistivity reduces dielectric losses and improves antenna radiation efficiency. Furthermore, high resistivity silicon wafers have the following promising characteristics: (a) uniform resistivity across the wafer thickness, (b) acceptable radial and axial resistivity gradients, and (c) stable resistivity during device production.

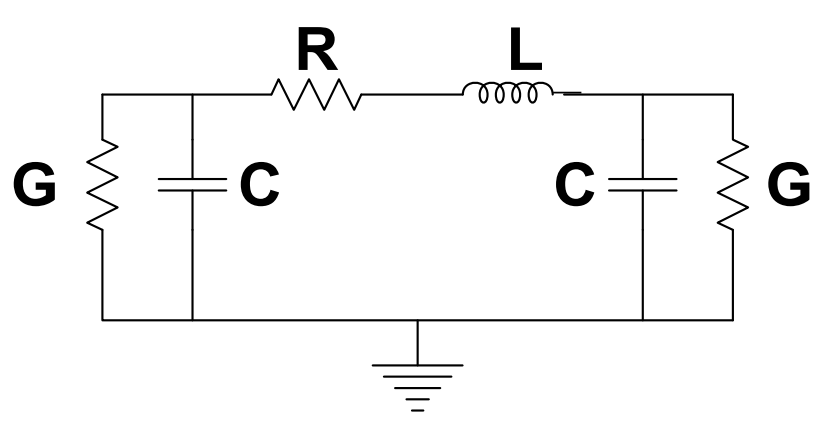

Fig. 2 Equivalent transmission model of Microstrip line

The present article describes the design of aperture coupled rectangular microstrip patch on silicon substrate coupled with performance improvement by the way of micromachining. Section II describes the design of aperture coupled and micro-machined antenna. The aspects of patch design, simulation, and fabrication, as well as measured findings, are covered in section III-V.

\section{THEORY OF APERTURE COUPLED MICRO-MACHINED ANTENNA}

The design of an aperture coupled microstrip patch can be done using a variety of analytical and design methodologies, such as transmission lines, cavity models, and so on [11-17]. Width $\left(\mathrm{W}_{\mathrm{ap}}\right)$ and length $\left(\mathrm{L}_{\mathrm{ap}}\right)$ of the slot determines coupling from the feed to the patch. Typically, the slot length to width ratio is $1: 10$. Wider slots result in back radiation. The length of the tuning stub compensates for the excess reactance of the slot. The stub length is typically slightly less than $\lambda g / 4$.

The Aperture coupled Micro-machined antenna configuration is shown in figure 3 .

In this configuration, an air cavity is formed beneath the microstrip patch by the process of micromachining. The process of micromachining causes synthesizing in effective dielectric constant due to mixed substrate region, i.e. airsilicon region. Effective dielectric constant can be predicted in the mixed region using a quasi-static model [11].

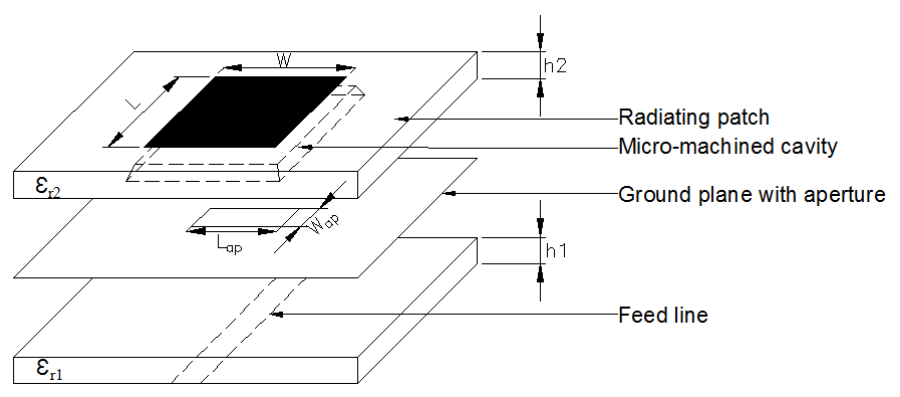

Fig. 3 Aperture coupled Micro-machined Microstrip patch antenna

The effective dielectric constant $\varepsilon_{r e f f}$ is estimated from the following expression:

$$
\begin{aligned}
& \varepsilon_{\text {reff }}=\varepsilon_{\text {cavity }}\left(\frac{L+2 \Delta L \frac{\varepsilon_{\text {fringe }}}{\varepsilon_{\text {cavity }}}}{L+2 \Delta L}\right) \\
& \frac{\varepsilon_{\text {fringe }}}{\varepsilon_{\text {cavity }}}=\frac{\varepsilon_{\text {air }}+\left(\varepsilon_{\text {sub }}-\varepsilon_{\text {air }}\right) x_{\text {air }}}{\varepsilon_{\text {air }}+\left(\varepsilon_{\text {sub }}-\varepsilon_{\text {air }}\right) x_{\text {fringe }}}
\end{aligned}
$$

Where:

$\varepsilon_{\text {cavity }}=\frac{\varepsilon_{\text {air }} \varepsilon_{\text {sub }}}{\varepsilon_{\text {air }}+\left(\varepsilon_{\text {sub }}-\varepsilon_{\text {air }}\right) x_{\text {air }}}$

$\varepsilon_{\text {cavity }}$ and $\varepsilon_{\text {fringe }}$ represents the relative dialectic constant of the mixed substrate region and the fringing field region respectively. $\Delta L$ indicates the open end effect. $x_{\text {fringe }}$ and $x_{\text {air }}$ are thickness parameters which are the ratio of the air to full substrate thickness in the fringing and mixed field regions, respectively.

A plot between $\varepsilon_{\text {reff }}$ and the $x_{\text {air }}$ for the silicon substrate is plotted in figure 4 . For $x_{\text {air }}$ of $0.44 \varepsilon_{\text {reff }}$ is 2 .

\section{PATCH DESIGN AND FABRICATION}


The design of the microstrip antenna on Si substrate employing CMOS process is briefed in the article [18]. Aperture coupled patch with and without micromachining is simulated on high resistivity $\mathrm{Si}$ substrate. High resistivity

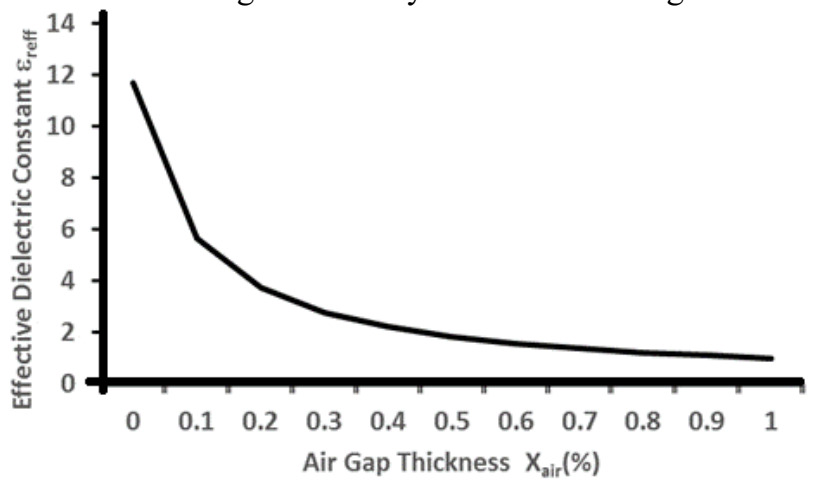

Fig. 4 Relationship between $\varepsilon_{\text {reff }}$ and $\mathrm{x}_{\text {air }}$

silicon substrate having $\varepsilon_{r}$ (11.9) with the height $(0.675$ $\mathrm{mm}$ ) selected for radiator and RT-Duroid 6010 with the height of 10 mils selected for feed. The design parameters and simulated results have been discussed in the following sections. The simulation setup of both patches is shown in figure 5 .

FDTD based CST simulator used for simulation and optimization of patch design [19]. The physical parameter of both designs is tabulated in Table 1. The depth of the micromachined cavity is $0.3 \mathrm{~mm}$ in design 2. The synthesized $\varepsilon_{r e f f}$ is 3.6 for the micromachined patch.

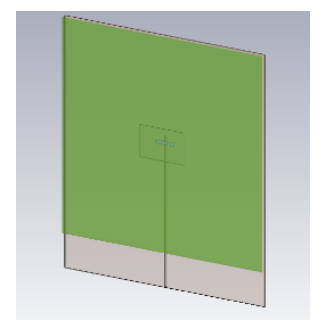

(a)

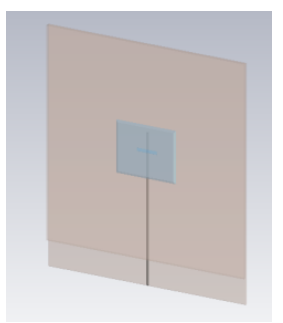

(b)
Figure 5:(a) Design1: Aperture Coupled Antenna, 4(b) Design 2: Micro-machined Aperture coupled Antenna

Table 1. Physical Parameters of Design 1 and 2

\begin{tabular}{|l|l|l|}
\hline Parameter & $\begin{array}{l}\text { Design1 } \\
\text { (Aperture } \\
\text { Coupled } \\
\text { Antenna) }\end{array}$ & $\begin{array}{l}\text { Design2 (Micro- } \\
\text { machined } \\
\text { Aperture coupled } \\
\text { Antenna) }\end{array}$ \\
\hline Width $(\mathrm{mm})$ & 6.8 & 11.25 \\
\hline Length $(\mathrm{mm})$ & 4.49 & 9.07 \\
\hline Slot Width $(\mathrm{mm})$ & .39 & 0.6 \\
\hline Slot Length $(\mathrm{mm})$ & 2.8 & 4 \\
\hline
\end{tabular}

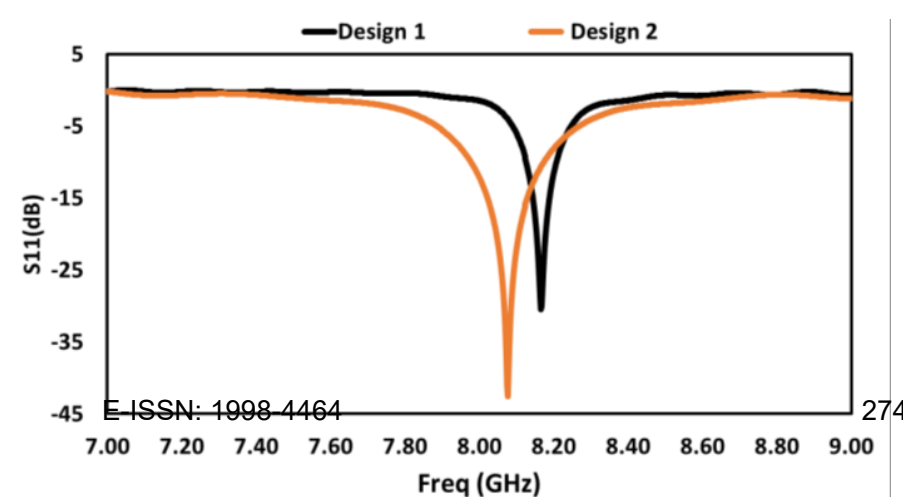

Feed Length $(\mathrm{mm})$

The simulated return loss plots for designs 1 and 2 are shown in Figure 6.

$\mathrm{E}(\mathrm{CO}$ pol $), \mathrm{H}(\mathrm{Cross}$ pol) plots for designs 1 and 2 are shown in Figure 7. Design 2 is with aperture coupled micromachined antenna.

Fig. 6 Return loss (Simulated)

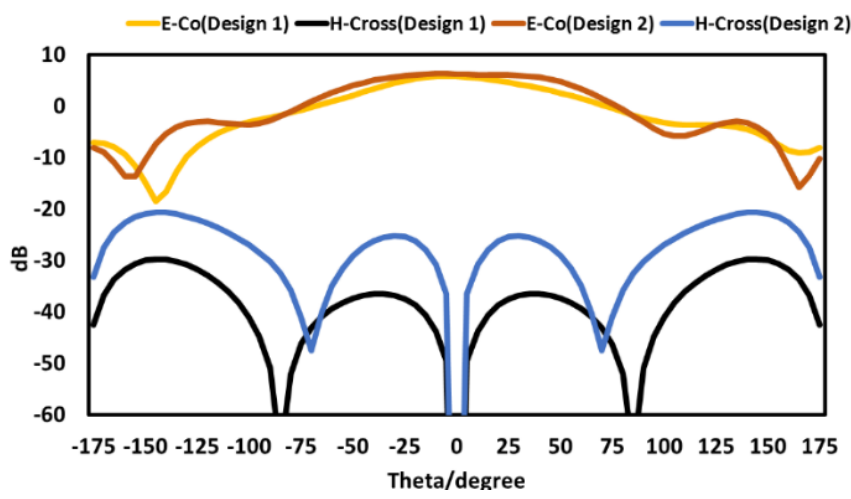

Fig. 7 E CO and H -Cross Pattern (Simulated)

By analyzing figures 6 and 7 the summary is tabulated in table 2 , it is evident that aperture coupled micro-machined antenna has 150, 9 and 5 percent more bandwidth, gain and efficiency respectively compated with aperture coupled antenna. Cross polarization performance is poorer due to the $54 \%$ wider slot.

Table 2. Simulated result comparison

\begin{tabular}{|l|l|l|}
\hline Parameter & Design 1 & Design 2 \\
\hline Resonant Freq.(GHz) & 8.17 & 8.1 \\
\hline Return Loss BW (MHz) & 80 & 200 \\
\hline Realized Gain (dB) & 5.8 & 6.1 \\
\hline Total Efficiency (\%) & 87 & 95 \\
\hline Cross Pol(dB) & 40 & 31 \\
\hline $\begin{array}{l}\text { E Plane 3 dB Beam Width } \\
\text { (degree) }\end{array}$ & 91 & 115 \\
\hline
\end{tabular}

For radiator fabrication, a double-sided polished 6" high resistivity $\mathrm{Si}$ wafer with a thickness of $0.675 \mathrm{~mm}$ was chosen. Si resistivity and dissipation factor $(\tan \delta)$ are in the 4-10 K Ohm and 0.021 ranges, respectively. A thin insulating layer of $\mathrm{SiO} 2$ with a thickness of $5000 \mathrm{~A}^{\circ}$ is placed over silicon to prevent the formation of a metalsemiconductor junction (Schottky Barrier), enhance metal adhesion, and reduce cross-talks in transmission lines.

The patch conductor material should have good adhesion properties to $\mathrm{Si} / \mathrm{SiO}_{2}$ and better corrosion resistance, so thick Aluminum $(3 \mu \mathrm{m})$ metallization using sputtering is used over buffer layer as a patch conductor. The fabrication process steps of the patch are explained in figure 8 .

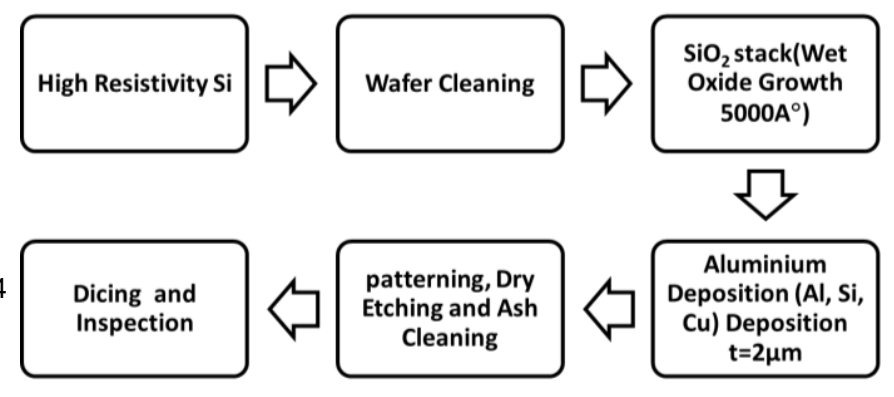


Fig. 8 Si Antenna fabrication Flow chart

Design 2 involves etching specific material from the backside of the patch using plasma etching, also known as the Deep Reactive Ion Etching (DRIE) method. DRIE is a bulk micromachining method for making steep-sided holes and trenches in wafers and substrates.

Another technique that is being used for micro-machining is wet chemistry ( $\mathrm{KOH} / \mathrm{TMAH})$ etching. The main difference between both the process is that the former is isotropic and time-consuming process.

Feed slot printed and etched on RT duroid 6010 substrate with a thickness of 10 mil.

The fabricated patches are showing in Figures 9 and 10.
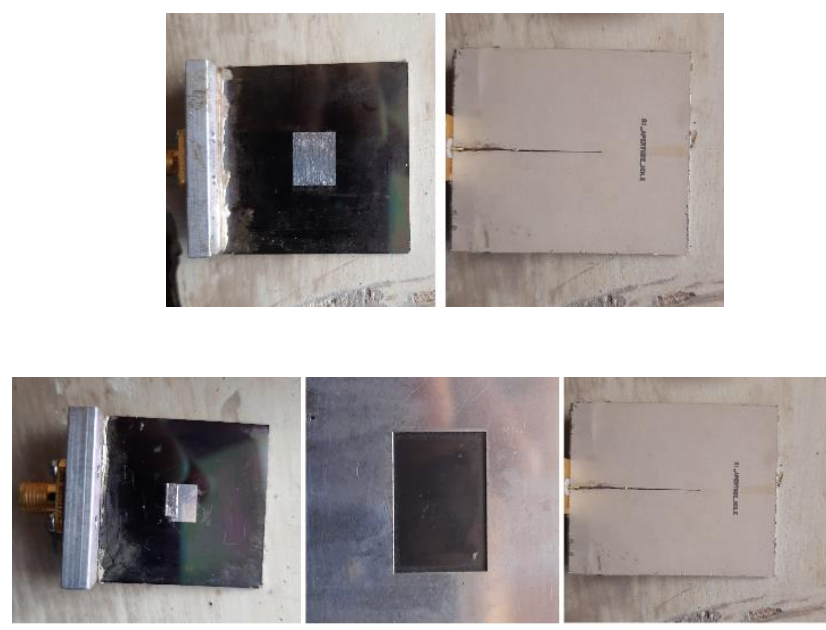

Fig. 9 Fabricated Aperture Coupled Antenna
(a) Patch
(b)Backside cavity
(c) Feed

Fig. 10 Fabricated Aperture Coupled Micro-machined Antenna

Henkel's "Able film 5025E" conductive adhesive sheet was used to connect the patch and feed line substrate. Feed launcher SMA connector attached by using normal process of soldering.

\section{EXPERIMENTAL RESULTS}

Return loss was measured in the frequency range of 7-9 $\mathrm{GHz}$ for both fabricated patches. Figures 11 and 12 show the calculated return loss statistics.

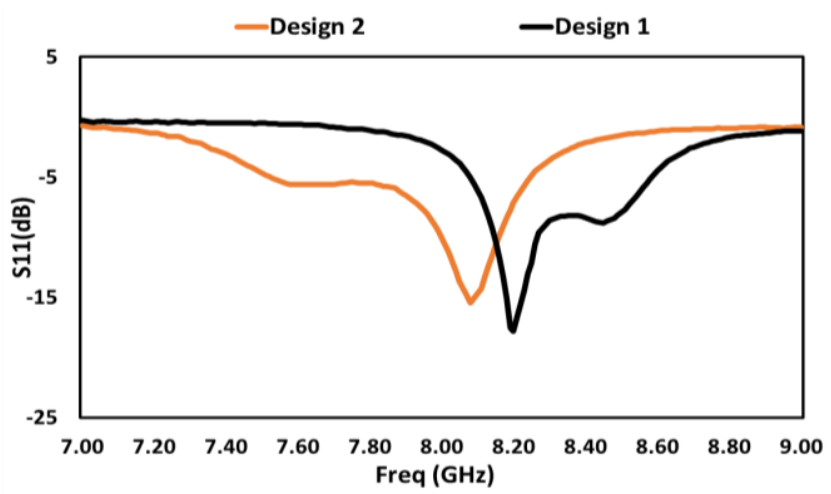

Fig. 11 Measured Return loss(dB)
$\mathrm{X}$ band standard horn antenna used to measure radiation pattern and gain in Anechoic Chamber. The measured E and $\mathrm{H}$ plane data for designs 1 and 2 are illustrated in figures 12 and 13.

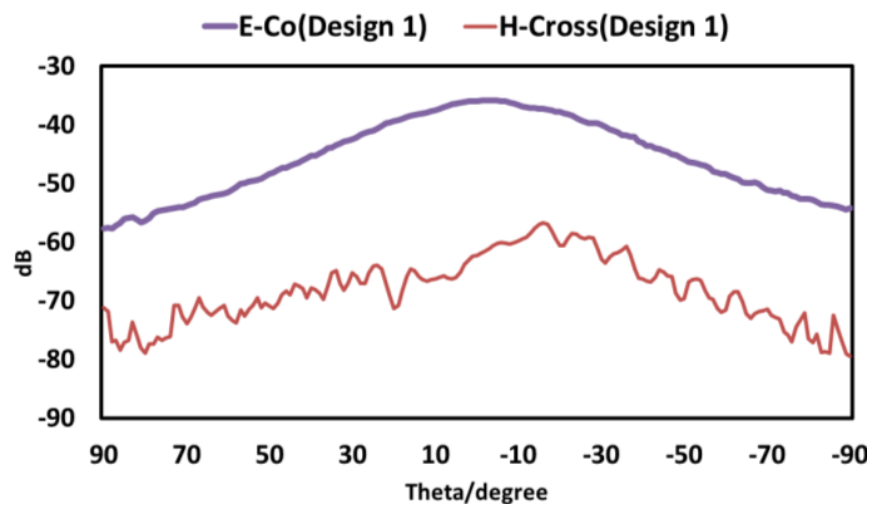

Fig. 12 Design 1: Measured Radiation pattern

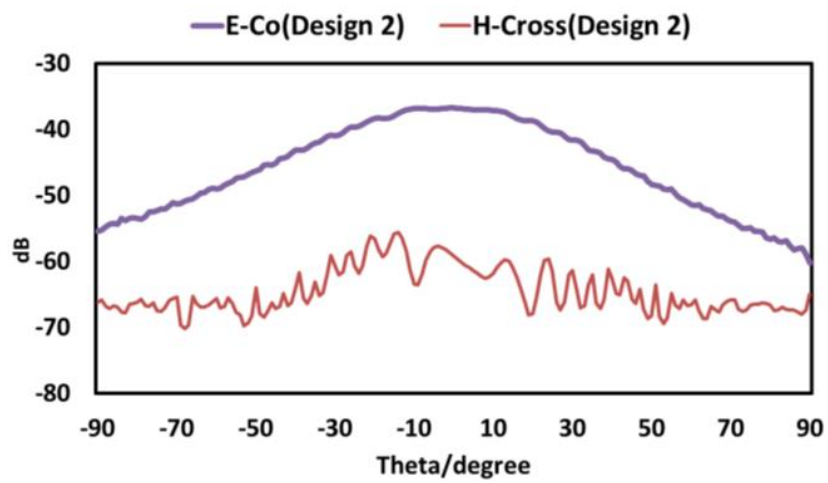

Fig. 13 Design 2: Measured Radiation pattern

The summary of measured results for both designs is tabulated in table 3 .

Table 3. Measurement Result Summary

\begin{tabular}{|l|c|c|}
\hline Parameter & Design 1 & Design 2 \\
\hline Centre Freq. (GHz) & 8.2 & 8.08 \\
\hline RL BW (MHz) & 125 & 170 \\
\hline Realized Gain (dB) & 5 & 5.9 \\
\hline $\begin{array}{l}\text { E plane 3 dB Beam Width } \\
\text { (Degree) }\end{array}$ & 50 & 70 \\
\hline Cross Pol (dB) & 25 & 20 \\
\hline
\end{tabular}

As per the measured results, it is evident that compared with design 1, design 2 which is a micromachined aperture coupled antenna having 36 percent and 18 percent more bandwidth and gain respectively. $3 \mathrm{~dB}$ beamwidth is also 40 percent more for design 2. Cross pol for design 2 is poor by 20 percent. It is due to the wider aperture slot area. The trend of the measurement results is having closeness to simulated results.

Designed patches are also compared with few identical references and tabulated in table 4.

Table 4. Comparison of Patches

\begin{tabular}{|l|l|l|l|l|}
\hline Patch & $\begin{array}{l}\text { Freq. } \\
(\mathbf{G H z})\end{array}$ & $\begin{array}{l}\text { Gain } \\
(\mathbf{d B i})\end{array}$ & $\begin{array}{l}\text { BW } \\
(\mathbf{\%})\end{array}$ & $\begin{array}{l}\text { Efficiency } \\
(\%)\end{array}$ \\
\hline Patch1 [7] & 12.8 & - & 5 & 73 \\
\hline Patch2[20] & 10 & 6.2 & 2 & - \\
\hline Patch3 [21] & 12 & 8.3 & 19 & $98^{*}$ \\
\hline Patch 4[23] & 10.35 & -1.38 & 7 & 55.8 \\
\hline Patch 5[24] & 35 & 5.8 & 4.19 & 74 \\
\hline Patch 6[25] & 62 & 6.7 & 4.3 & 73 \\
\hline
\end{tabular}




\begin{tabular}{|l|l|l|l|l|}
\hline Patch 7[26] & 94 & - & 10 & 58 \\
\hline Patch 8[27] & 60 & 7 & $2.33-6.16$ & $86-73$ \\
\hline Patch 9[28] & 35.4 & - & 3.38 & - \\
\hline Patch [29] & 36 & - & 2.77 & - \\
\hline Patch [30] & 35 & - & 3.4 & - \\
\hline Patch [31] & 34.2 & 8.5 & 4 & 92 \\
\hline Patch [32] & 94 & 10.5 & 25 & 92 \\
\hline Patch [33] & 28 & 8.04 & 3.67 & 97.7 \\
\hline $\begin{array}{l}\text { Present } \\
\text { work } \\
\text { (Design 1) }\end{array}$ & 8.2 & 5 & 1.5 & $87^{*}$ \\
\hline $\begin{array}{l}\text { Present } \\
\text { work } \\
\text { (Design 2) }\end{array}$ & 8.08 & 5.9 & 2.03 & $95^{*}$ \\
\hline
\end{tabular}

* Simulated

Implementation of micromachining in aperture coupled patch helps in, reduction in losses, suppression of surface waves and substrate modes, results in an improvement in space wave radiation. The alignment of the patch and feed substrate is very critical for optimum performance. The possible variation in the measurement result is due to the minor misalignment of the patch with the feed substrate, which was carried out manually.

Comparison of patches are tabulated in table 4, the concept of micro-aching with aperture coupling can be extended to the higher band and multiband [34] of frequencies, where improvement in the percentage bandwidth and radiation characteristics is observed.

\section{CONCLUSION}

Aperture coupled antenna with and without micromachining are realized at X-band and comparative analysis is presented. Micromachining facilitates the improvement in return loss bandwidth and the gain of the order of 36 percent and $1 \mathrm{~dB}$ respectively. 40 percent more beamwidth is achieved using the micromachined antenna. This article demonstrates the effectiveness of the micromachining technique to achieve wider bandwidth, higher gain and efficiency compared to standard aperture coupled antenna. This improvement is due to the suppression of surface waves, reduction in losses and substrate modes. Standard micromachined patch antenna performance is compromised due to feed radiation. The present approach provides flexibility in optimizing feed and patch separately. This work can be further extended at $\mathrm{Ku}$, $\mathrm{Ka}$ and the higher band of the frequencies, where the substrate losses are predominant and antenna size is comparable to the wavelength. It was observed the physical dimension of the micromachined patch is bigger, so the losses associated with the smaller dimension shall be reduced. In this article design aspects, simulation and measurement results of the realized topologies are detailed. Further viability of silicon as an effective substrate for aperture coupled topology is established and it will further pave the way for implementation of complete topology on silicon leading towards smart system development for satellite, mobile communication systems. Micromachining approach can be further extended for efficient array design as well as multi-frequency design. Patch array with multiple micromachined patch will lead to effective array with improved performances at microwave frequencies.

\section{ACKNOWLEDGEMENT}

Authors sincerely thank and acknowledge the support provided by the various entities of URSC and SCL. Authors gratefully acknowledge the support of Manipal University Jaipur for providing the CST software for doing the literature work and simulation.

\section{REFERENCES}

[1] Pozar, David M. "Microstrip antennas." Proceedings of the IEEE 80, no. 1 (1992): 79-91.

[2] Howell, J. "Microstrip antennas." IEEE Transactions on Antennas and Propagation 23, no. 1 (1975): 90-93.

[3] James, James R., Peter S. Hall, and Colin Wood. Microstrip antenna: theory and design. Vol. 12. Iet, 1986.

[4] Rathi, Amit, and Ritu Vijay. "Expedite particle swarm optimization algorithm (EPSO) for optimization of MSA." In International Conference on Swarm, Evolutionary, and Memetic Computing, pp. 163-170. Springer, Berlin, Heidelberg, 2010.

[5] Pozar, David M. "A review of aperture coupled microstrip antennas: History, operation, development, and applications." University of Massachusetts at Amherst (1996): 1-9.

[6] Hyltin, Tom M. "Microstrip transmission on semiconductor dielectrics." IEEE Transactions on Microwave Theory and Techniques 13, no. 6 (1965): 777-781.

[7] Papapolymerou, Ioannis, R. Franklin Drayton, and Linda PB Katehi. "Micromachined patch antennas." IEEE Transactions on Antennas and Propagation 46, no. 2 (1998): 275-283.

[8] Soni, Brijesh Kumar, Kamaljeet Sing, Amit Rathi, and Sandeep Sancheti. "CMOS Compatible Techniques for Patch Antennas Realization on Silicon." In 2021 2nd International Conference for Emerging Technology (INCET), pp. 1-5. IEEE, 2021.

[9] Buechler, Joseph, Erich Kasper, Peter Russer, and Karl M. Strohm. "Silicon high-resistivity-substrate millimeter-wave technology." IEEE Transactions on Electron Devices 33, no. 12 (1986): 2047-2052.

[10] Ayan Karmakar, Kamaljeet Singh, "Si-RF Technology", Springer Nature, 2019

[11] Garg, Ramesh, Prakash Bhartia, Inder J. Bahl, and Apisak Ittipiboon. Microstrip antenna design handbook. Artech house, 2001.

[12] Mosig, Juan R., and Fred E. Gardiol. "Analytical and numerical techniques in the Green's function treatment of microstrip antennas and scatterers." In IEE Proceedings H (Microwaves, Optics and Antennas), vol. 130, no. 2, pp. 175-182. IET Digital Library, 1983.

[13] K. R. Carver and J. W. Mink, "Microstrip Antenna Technology," IEEE Trans. Antennas Propagat., Vol. AP-29, No. 1, pp. 2-24, January 1981.

[14] E. H. Newman and P. Tylyathan, "Analysis of Microstrip Antennas Using Moment Methods," IEEE Trans. Antennas Propagat., Vol. AP29, No. 1, pp. 47-53, January 1981

[15] C. A. Balanis, Advanced Engineering Electromagnetics, JohnWiley \& Sons, New York, 1989.

[16] Hammerstad, Erik O. "Equations for microstrip circuit design." In 1975 5th European Microwave Conference, pp. 268-272. IEEE, 1975.

[17] Terry C. Edwards, Michael B. Steer, "Foundations for Microstrip Circuit Design, John Wiley and Sons, 2016

[18] Soni, Brijesh Kuamr, P. Ravi Teja Naidu, and Sandeep Sancheti. "Xband rectangular microstrip patch antenna on Si substrate using IC process." In 2017 IEEE International Conference on Antenna Innovations \& Modern Technologies for Ground, Aircraft and Satellite Applications (iAIM), pp. 1-4. IEEE, 2017.

[19] Studio, CST Microwave. "3D EM Simulation software." Computer Simulation Technology (2017).

[20] Manoj Singh, Ananjan Basu, and S.K. Koul, Design of Aperture Coupled Fed Micro-Strip Patch Antenna for Wireless Communication, , 2006 Annual IEEE India Conference

[21] S. K. Pavuluri, C. H. Wang, and A. J. Sangster, A High-Performance Aperture-Coupled Patch, Antenna Supported by a Micromachined Polymer Ring, IEEE antennas and wireless propagation letters, vol. 7, 2008

[22] Peter.L.Sullivan, Daniel H.Schaubert,Analysis of an aperture Coupled Microstrip Antenna, IEEE TRANSACTIONS ON ANTENNAS AND PROPAGATION, VOL. AP-34, NO. 8. AUGUST 1986. 
[23] Micro-machined 3D Cube Antenna for X-Band Communication ICs, Yuxin Wang, Han-yu Tsao, Noah Sauber, Robert M. Weikle, Arthur W. Lichtenberger and N. Scott Barker, IEEE 21st Annual wireless and microwave technologies confenence(WAMICON 2021).

[24] HOU Fang, ZHU Jian, YU Yuan-wei1 WU Jing, Millimeter-wave Design of Aperture-coupled Micromachined Patch Antennas, 11 ICMMT 2008 Proceedings

[25] Nolwenn Caillet, Stephane Pinel, Cedric Quendo, Christian Person, Eric Rius, Jean-Francois Favennec and Joy Laskar, Foam Micromachined Aperture-Coupled Antennas for V-Band Low-Cost Applications, Proceedings of the 37th European Microwave Conference IEEE, transactions on antennas and propagation, vol. 47, NO. 12, DECEMBER 19991761

[26] Gildas P. Gauthier, Jean-Pierre Raskin, ,Linda P. B. Katehi, and Gabriel M. Rebeiz,A 94-GHz Aperture-Coupled Micromachined Microstrip Antenna, IEEE Transactions on Antennas and Propagation ( Volume: 47, Issue: 12, Dec 1999)

[27] Mai O. Sallam, Ezzeldin A. Soliman, Reconfigurable Micromachined On-Chip Antenna with Radiation Pattern Diversity, 2013 7th European Conference on Antennas and Propagation (EuCAP).

[28] Preeti Sharma , Shiban K. Koul and Sudhir Chandra, Ka-band Triangular Patch Antenna on Micromachined High-K Substrate, International Symposium on Antennas and Propagation - ISAP 2006

[29] Shiban K Koul, Design and development of passive and active RF components using MEMS technology, " 2007 International Workshop on Physics of Semiconductor Devices.

[30] Sharma, Preeti, and Shiban K. Koul. "Design and development of millimeter-wave micromachined patch antennas." IETE Journal of Research 55, no. 1 (2009): 40-50.

[31] Singh, Vinod Kumar. "Ka-band micromachined microstrip patch antenna." IET microwaves, antennas \& propagation 4, no. 3 (2010): 316-323.

[32] Bunea, Alina-Cristina, Dan Neculoiu, Andrei Avram, and Mihai Iovea. "Wideband Micromachined Antenna for W-band Applications." In 2018 IEEE Asia-Pacific Conference on Antennas and Propagation (APCAP), pp. 433-434. IEEE, 2018.

[33] Mohamed F. Abdulmajid, Study and Analysis of Rectangular Microstrip Patch Antenna at $28 \mathrm{GHz}$ for $5 \mathrm{G}$ Applications, WSEAS Transactions on Communications, ISSN / E-ISSN: 1109-2742 / 2224 2864, Volume 20, 2021, Art. \#2, pp. 6-11.

[34] Ambresh P. Ambalgi, Sujata S. K., Arti Vaish, Experimental and Simulation Study of Effects in Etched Patch Antenna with Multi Slots, WSEAS Transactions on Communications, ISSN / E-ISSN: 1109-2742 / 2224-2864, Volume 19, 2020, Art. \#16, pp. 142-148.

\section{Creative Commons Attribution License $\mathbf{4 . 0}$ (Attribution 4.0 International, CC BY 4.0)}

This article is published under the terms of the Creative Commons Attribution License 4.0 https://creativecommons.org/licenses/by/4.0/deed.en_US 